\title{
COMPENSACIÓN DEL DAÑO MORAL "PURO" DE LAS VÍCTIMAS SECUNDARIAS O POR REBOTE. COMENTARIOS COMPARADOS EN DERECHO INGLÉS Y FRANCÉS CORTE SUPREMA, 24 DE ENERO DE 2019, ROL N. ${ }^{\circ} 38.037-2017$
}

\section{COMPENSATION OF "PURE" EMOTIONAL DISTRESS CLAIMED BY SECONDARY VICTIMS. A COMPARATIVE OVERVIEW OF ENGLISH AND FRENCH LAW. CASE COMMENT: CHILEAN SUPREME COURT, JANUARY 24, 2019, $\mathrm{N}^{\circ} 38037-2017$}

\author{
Arantxa Gutiérrez"
}

\section{Resumen}

Marcando un alejamiento de las hipótesis tradicionales de muerte o lesiones de la víctima inicial, la Corte Suprema compensó el daño moral por rebote sufrido por la familia directa de una persona a quien el noticiario central de un canal de televisión erradamente atribuyó la comisión de un delito. Una revisión del marco normativo actual de protección del honor y la reputación permite evaluar la estructura de los perjuicios extrapatrimoniales compensados, distinguiendo entre una estructura normativa y otra consecuencial de los mismos y, de igual modo, apreciar en qué medida el daño moral "puro" es compensado en Chile. De igual manera se exponen las limitaciones impuestas en ordenamientos jurídicos como el inglés y francés, tanto respecto de las materias respecto de las cuales procede demandar daño moral por rebote, como las restricciones en términos de legitimación activa. Todo ello permite vislumbrar de qué manera el sistema chileno muestra signos de ser uno de los más liberales del mundo en cuanto a la amplitud de la compensación del daño moral, siendo este uno entre muchos otros ejemplos.

* Abogada, Universidad de Chile. Magíster en Derecho Privado Comparado y Europeo, Universidad de Edimburgo, Escocia. Candidata a Doctora en Derecho, Universidad de Edimburgo, Escocia. Becaria ANID para estudios de Doctorado en el Extranjero (2016). Tutora del curso de Derecho de Responsabilidad escocés. Dirección postal: Edinburgh Law School, University of Edinburgh, Old College, South Bridge, Edinburgh, EH8 9YL. Correo electrónico: a.gutierrez@ed.ac.uk. Este trabajo se sometió a Double blind review, y fue recibido el 16 de septiembre de 2019 y aceptado para su publicación el 26 de febrero de 2020. 
Palabras clave: daño moral; víctima por rebote; derecho comparado; protección del honor; protección de la reputación; pérdidas extrapatrimoniales; perjuicios normativos; perjuicios consecuenciales.

\begin{abstract}
Moving away from the traditional cases dealing with death or injury of the primary victim, the Chilean Supreme Court compensated the non-pecuniary losses suffered by the wife and children of a man who was wrongly accused of being the author of a crime in the evening news emission of a national television broadcaster. A review of the current framework of protection given to honour and reputation will be useful to assess the structure of the compensation of non-pecuniary losses, distinguishing between normative and consequential ones, as well as highlighting to what extent "pure" moral losses are redressed. Additionally, the limitations imposed by other jurisdictions such as English and French law will be outlined, focusing on both the cases where secondary victims can claim such losses, as well as the restrictions imposed on the class of persons who can make such claims. All this will expose how the Chilean legal system shows signs of being one of the most liberal of the world regarding the breadth of the compensation of non-pecuniary losses, this being only one example among many others.
\end{abstract}

Keywords: non-pecuniary losses; pure emotional loss, secondary victims; comparative tort law; protection of honour; defamation; normative losses; consequential losses, taxonomy.

\title{
I. INTRODUCCIÓN
}

Una precisión preliminar de importancia para circunscribir de forma adecuada el presente caso, está relacionada con evitar confundirlo con la diseminación de "noticias falsas" en el sentido del neologismo del inglés fake neres'. Aun cuando la información al centro de la controversia es objetivamente falsa, ello se debe a negligencia por parte de la demandada, Chilevisión S.A., quien atribuyó de manera errónea la autoría del delito de homicidio al demandante.

${ }^{1}$ Este concepto emergente en la literatura académica ha sido caracterizado de diversas maneras, la mayoría de las cuales pueden resumirse en seis tipos de definiciones: 1. noticias satíricas, 2 . noticias tipo parodia, 3 . invenciones, 4 . manipulación, 5 . publicidad y 6 . propaganda. Para una revisión bibliográfica de las definiciones académicas existentes entre 2003 y 2017, véase TANDOC, Lim \& Ling (2018), pp. 137-153.

Resulta claro que el caso objeto del presente comentario no corresponde a ninguna de estas categorías, ni resulta de una conducta intencionada de desinformación por parte del canal de televisión, por lo cual cabe desechar cualquier referencia a "noticias falsas" en los sentidos antes mencionados. 
En definitiva, no se está en presencia de daño moral producto de "noticias falsas", sino, mejor dicho, es este un caso paradigmático, y bastante tradicional, de afectación de la reputación de la víctima y daño moral consecuencial debido a la publicación negligente de información inexacta.

Desde un punto de vista sustantivo, una visión comparada del presente caso permite vislumbrar en que medida el derecho chileno se ha erguido en uno de los más liberales del mundo en cuanto a la compensación del daño moral. Con este propósito, y de modo de facilitar la comparación, será delineado el marco teórico que permite dividir los perjuicios extrapatrimoniales en dos grandes grupos: perjuicios normativos, por un lado, y perjuicios consecuenciales, por el otro. De manera adicional se ensayará una breve caracterización del marco de protección del honor y la reputación tanto en Francia como Inglaterra y Gales, y de qué manera ello se diferencia de la situación chilena. Por último, serán destacadas las limitaciones a la compensación de las denominadas víctimas secundarias (indirectas o por rebote) en dichas jurisdicciones, lo cual proveerá una idea más clara de la posición liberal adoptada por la Corte Suprema chilena.

\section{LA CUESTIÓN DEBATIDA}

\section{Hechos relevantes}

La controversia en el presente caso surge producto de la emisión por parte del canal de televisión Chilevisión de una noticia objetivamente falsa. En los hechos, a fines de marzo de 2012, el demandante conducía su vehículo por la autopista, acompañado de su cónyuge y tres hijos, dos de los cuales eran menores de edad. Mientras se hallaba en desplazamiento, una serie de otros vehículos encendió sus respectivas luces intermitentes, luego de lo cual, de modo repentino el demandante fue sorprendido por el cuerpo de una persona semidesnuda tendida en la autopista justo en frente suyo. Producto de la velocidad a la cual se desplazaban, y a pesar de maniobrar el vehículo de modo de esquivarlo, el cuerpo fue embestido con una de las ruedas traseras. La persona en cuestión había sido víctima de una pelea al interior de un bus que transitaba por la autopista, producto de la cual el hombre fue arrojado por el parabrisas trasero del bus en movimiento, produciéndose su muerte inmediata. Sin embargo, al reportar la noticia la emisión del noticiero central de Chilevisión sindicó al Sr. Valls, el demandante, como la persona que habría empujado a la víctima desde el bus, agregando, además, que se hallaba detenido. Al momento de la demanda, en abril de 2013, la noticia seguía manteniéndose en el sitio Internet de Chilevisión a pesar de que el verdadero autor del homicidio ya había sido condenado por el Juzgado de Garantía de Villa Alemana. También resulta de relevancia para el presente comentario, hacer notar la existencia de un requerimiento de inaplicabilidad 
por inconstitucionalidad presentado por el señor Valls respecto del art. 2331 del Código Civil, el cual fue acogido².

\section{La cuestión jurídica discutida}

La demanda es interpuesta por la víctima directa, y por su cónyuge y tres hijos en calidad de víctimas "por rebote" ${ }^{3}$. La Corte Suprema dictó sentencia de reemplazo aumentando el monto de la indemnización de la víctima principal, y otorgando indemnización del daño moral a las víctimas por rebote, quienes no habían sido compensadas en primera instancia, ni tampoco por la Corte de Apelaciones, que confirmó el fallo del tribunal inferior ${ }^{4}$.

Sobre la base de la cláusula general de responsabilidad contenida en los arts. 2314 y 2329 del Código Civil, la Corte definió que la cuestión relevante en este caso era la determinación de si el daño moral experimentado por las víctimas secundarias había quedado establecido o no ${ }^{5}$. Por otro lado, se indica que los padecimientos que constituyen el daño moral tienen su origen en la información divulgada por la estación de televisión. Además, se agrega que al divulgar tal noticia la demandada habría infringido el deber general de cuidado que se encontraba obligada a respetar.

Es de interés destacar que los considerandos de la sentencia de prime220 ra instancia que fueron revertidos por la Corte Suprema son aquellos que refieren a la prueba requerida para la indemnización del daño moral de las víctimas por rebote. El tribunal inferior argumentó que la prueba rendida no permitía acreditar los daños morales reclamados, en cuanto solo dos de los nueve testimonios ofrecidos daban cuenta de un cambio en la personalidad de los demandantes, el resto siendo testimonios "de oídas" estos diesen razón de sus dichos?.

${ }^{2}$ Tribunal Constitucional, 6 de julio de 2015, rol n. ${ }^{\circ} 2860$.

${ }^{3}$ Para fundamentar la distinción entre víctima directa e indirecta, en considerandos que no son afectados por la resolución de la Corte Suprema $\left(30^{\circ}\right.$ y $\left.31^{\circ}\right)$, el tribunal de primera instancia, siguiendo en esto a ElORRIAGA (1999), señala que como consecuencia de un ilícito civil contra la víctima inicial en muchos casos pueden producirse tanto perjuicios de carácter material como moral, donde la víctima por repercusión o rebote tiene un derecho originario a demandar la reparación del propio daño. Para ello se basa en jurisprudencia anterior, la cual indica: "tratándose de daño moral pueden demandar su reparación la víctima inmediata o directa, esto es, o sí la persona misma en quien recae la lesión, ofensa o injuria que lo causa, y los que sin tener esa calidad también lo sufren en razón de que el daño inferido a aquélla los hiere en sus propios sentimientos o afectos, incluso aun cuando no sean sus herederos o parientes" (CS, 15 de diciembre de 1983. Revista de Derecho y Jurisprudencia, tomo 80, sec. $1^{\mathrm{a}}$, p. 128).

${ }^{4}$ El daño moral de la víctima principal fue valorado por la Corte Suprema en $\$ 32000000$. El de su cónyuge, en $\$ 5000000$, mientras que el de sus tres hijos fue estimado en $\$ 3000000$ cada uno.

${ }^{5}$ Corte Suprema, 24 de enero de 2019, rol n. ${ }^{\circ} 38.037-2017$, n. ${ }^{\circ} 1$.

${ }^{6} 17^{\mathrm{o}}$ Juzgado Civil de Santiago, 30 de agosto de 2016, rol C-4309-2013, cons. $38^{\circ}$.

${ }^{7}$ Op. cit., cons. $39^{\circ}$. 
Para revertir tal decisión, la Corte Suprema se basó en el "principio de normalidad" en materia probatoria, el cual redundaría en que quien alega lo extraordinario debe probarlo, mientras que aquella parte que alega lo normal u ordinario no tendría tal obligación ${ }^{8}$. Para ejemplificar, el tribunal recurre al art. 1698 del Código Civil, el cual, argumenta, tendría aplicación más allá de la prueba de las obligaciones. En este sentido, el razonamiento discurre en que lo "normal" en un caso como el presente sería que no solo la persona que percibe una noticia grave en los medios de comunicación masiva, en horario punta y donde se le atribuye la comisión de un delito del cual no ha participado, sufra angustia, sino, también, su familia. La Corte concluye que es normal que el sufrimiento que "padece un sujeto por unos hechos como los de esta causa constituya un daño que también padecerán su cónyuge y sus hijos", lo cual hace que el que se haya alegado la extemporaneidad de la prueba sea totalmente irrelevante.

\section{COMENTARio}

\section{Dos modelos teóricos para explicar la diversidad de manifestaciones del daño moral: perjuicios normativos y perjuicios consecuenciales}

Una variedad de sistemas jurídicos, tanto del lado del derecho civil de tradición romano-canónica como del Common Law, exhiben una gran diversidad de manifestaciones de pérdidas no pecuniarias. Detrás de la apariencia unitaria de conceptos como daño moral, préjudices morales o non-pecuniary losses, en realidad se esconde una miscelánea de perjuicios, los cuales operan a diferentes niveles de abstracción.

A grandes rasgos, estos pueden organizarse bajo dos ópticas, una deóntica (o unipolar) y otra consecuencial (o bipolar ${ }^{10}$. Encuadrado en el primer modelo, el perjuicio está representado por la infracción de un interés jurídicamente protegido, de modo que el perjuicio puede calificarse como normativo, pues la sola infracción de tal interés desencadena la responsabilidad civil, sin que la parte afectada se halle en la necesidad de probar los perjuicios concretos que fluyen de manera consecuencial al daño. Es por esto que bajo tal óptica, los perjuicios son descritos como abstractos, lo cual, en definitiva, significa que daño y perjuicio devienen la misma cosa, se confunden o superponen.

Por contraste, en muchos casos distintos sistemas jurídicos optan por compensar los perjuicios extrapatrimoniales bajo una lógica consecuencial o bipolar. Ello redunda en una separación teórica entre el ilícito y los perjui-

${ }^{8}$ Corte Suprema, 24 de enero de 2019, rol n. ${ }^{\circ} 38.037-2017$, n. ${ }^{\circ} 4$.

${ }^{9}$ Op. cit., n. ${ }^{\circ} 5$.

${ }^{10}$ Para una exposición más detallada de ambos modelos teóricos y su aplicabilidad tanto en el derecho civil como el Common Law, véase Descheemaeker (2016). 
cios que fluyen como resultado este. De tal forma, significa que el hecho que genera el daño puede producir tanto perjuicios patrimoniales como extrapatrimoniales, lo cual en términos de compensación lleva a que la atención recaiga en sus manifestaciones concretas. En gran medida los casos de daño corporal operan bajo esta lógica, y un número de manifestaciones de pretium doloris en realidad reflejan pérdidas concretas derivadas de la infracción a la integridad física de una persona, bajo las formas de dolor, molestias, ansiedad, enfermedades psiquiátricas, entre otras ${ }^{11}$.

En este caso, de manera bastante clara la atención se centra en los perjuicios concretos que fluyen de forma consecuencial al daño, agregándose por parte del tribunal de primera instancia la necesidad de acreditar la existencia real y efectiva del perjuicio ${ }^{12}$. De igual modo, son enumeradas de forma explícita una serie de manifestaciones concretas de perjuicios consecuenciales ${ }^{13}$, estando también ante la Corte Suprema el énfasis en los efectos concretos del ilícito. Sin embargo, a diferencia de lo que sucede en primera instancia, donde la compensación de las víctimas secundarias es negada por motivos de prueba ${ }^{14}$, ante el máximo

${ }^{11}$ En Chile, este es el modelo dominante de compensación del daño moral sufrido por personas naturales. En otros países, como Francia, la lógica bipolar es apreciable en las categorías de perjuicios empleadas por las Cortes en casos de daño corporal (ejemplo de ello es apreciable en la llamada nomenclature Dintilhac). En tal nomenclatura los perjuicios designarían de manera más precisa las consecuencias patrimoniales o extrapatrimoniales del hecho dañoso, destacándose entre las últimas perjuicios concretos tales como perjuicio sexual, perjuicio estético, perjuicio de agrado, entre otros. Véase Lambert-Faivre, Porchy-Simon (2015), p. 430. Por contraste, las infracciones a los derechos de la personalidad generalmente operan bajo una concepción abstracta donde la sola infracción del interés jurídico protegido desencadena la respuesta del sistema de responsabilidad.

${ }^{12} 17^{\circ}$ Juzgado Civil de Santiago, 30 de agosto de 2016, rol C-4309-2013, cons. 33º: "Que en consecuencia, desde la perspectiva del derecho a accionar judicialmente reconocido por la Carta Fundamental en su art. $19 \mathrm{~N}^{\mathrm{o}} 3$, garantía que en este ámbito debe interpretarse armónicamente con los artículos 2314 y 2329 del Código Civil que establecen el derecho a demandar la reparación de todo daño imputable a malicia o negligencia de otra persona, no puede descartarse a priori la procedencia de las acciones deducidas por supuestas víctimas indirectas -en la especie los tres hijos y cónyuge del Sr. Valls-, sin perjuicio que, como se dijo anteriormente, éstas deban acreditar la existencia real y efectiva del perjuicio que reclaman haber sufrido".

${ }^{13} \mathrm{Op.} \mathrm{cit}$., cons. $34^{\circ}$ : "...los actores manifiestan que han sufrido un daño moral evidente, injusto, que se ve reflejado en el dolor, angustia, depresión, desesperación, vergüenza, menoscabo espiritual, psíquico y físico, imposibles de describir y difíciles de apreciar en su magnitud pero que en todo caso son reparables civilmente atendida la magnitud de los bienes extrapatrimoniales conculcados por el hecho negligente de la demandada".

${ }^{14} \mathrm{Op}$. cit., cons. $38^{\circ}$ : "Que luego, con el objeto de acreditar la efectividad de haber padecido efectivamente los daños morales que alegan los actores, estos sólo rindieron la prueba testimonial (...) que valorada legalmente conforme a lo dispuesto en los artículos 383 y 384 del Código de Procedimiento Civil, no permite a esta sentenciadora concluir, inequívocamente y con la certeza requerida por el derecho, que la cónyuge e hijos del Sr. Claudio Valls hayan sufrido un daño moral indemnizable. Que en este sentido, sólo dos de los nueve testigos manifestaron que les constaba un cambio en la personalidad de los integrantes de la familia Valls Frez (...) Los restantes testimonios tienen la naturaleza 'de oídas' y que no constan a sus declarantes, de manera tal que sobre este punto, no se les puede dar la fuerza probatoria a fin de tener por ciertos las condiciones de reparabilidad de los daños morales reclamados". 
tribunal se dispensa de esta, no porque no sea en principio necesaria, sino como se mencionaba con anterioridad, sobre la base de que quien alega lo normal u ordinario no debe probarlo, por aplicación de la lógica que subyace al art. 1698 del Código Civil. Entre otras cosas, ello demuestra la extraordinaria amplitud del modelo chileno de compensación del daño moral de las víctimas indirectas. La argumentación de la Corte no está anclada en un modelo deóntico donde lo que importa es la identificación del interés jurídico protegido que ha sido conculcado respecto de cada víctima en particular, y en cuyo caso la prueba de perjuicios consecuenciales es irrelevante, sino como a lo largo de este trabajo la atención está puesta en los perjuicios concretos. Esto produce un desajuste en el sistema de responsabilidad, ya que al hacer irrelevante su prueba, la víctima secundaria es reparada por las molestias sufridas a consecuencia del la conducta negligente de la demandada que difamó a la víctima principal, pues simplemente "(...) lo normal y corriente es que el cuasidelito cometido por la demandada provoque los padecimientos y menoscabos descritos" ${ }^{15}$. En este sentido, lo vulnerado no sería un derecho de la personalidad de la víctima secundaria, que genera perjuicios tanto patrimoniales como extrapatrimoniales, sino en presencia de daño moral "puro".

Como es posible apreciar, si se diera carácter universal a tal principio ello redundaría en que los familiares cercanos de la víctima directa tendrían que ser compensados en una multiplicidad de otros casos: es de suponer que es igualmente normal que experimenten ansiedad o malestar psíquico los cercanos a una víctima de cualquier lesión corporal significativa o infracciones a la integridad física, a la libertad personal, entre muchísimos otros ejemplos. Ello, aparejado con una falta de calificación en la edad de las víctimas secundarias, lleva a que en el caso en comento, la hija de tres años al momento de la emisión de la noticia y su hermano mayor de edad sean compensados por el mismo monto de dinero. Si el demandante tuviera doce hijos en vez de tres, uno podría suponer que cada uno de ellos habría recibido reparación del daño moral por rebote, sin importar que uno tuviese seis meses de edad, cuarenta años o la ausencia de acreditación de haber sufrido los perjuicios alegados. Planteado en términos de limitación de la responsabilidad civil, el riesgo de abrir las puertas a un número indeterminado de potenciales víctimas secundarias es claro. Sin una definición positiva de daño moral, y en ausencia de una reflexión doctrinaria más robusta respecto de los fundamentos y funciones de la responsabilidad civil extracontractual, el sistema jurídico chileno está derivando hacia consideraciones punitivas del daño moral. Universalizar el principio jurídico detrás de la decisión contenida en esta sentencia parece riesgoso respecto de demandados que no son un canal de televisión consolida-

Cons. $39^{\circ}$ : “(...) los referidos testigos no dan razón de sus dichos, de manera tal que esta sentenciadora rechazará las reclamaciones de daño moral de (...) [la] cónyuge de la víctima inmediata, y sus tres hijos (...)”.

${ }^{15}$ Corte Suprema, 24 de enero de 2019 , rol n. ${ }^{\circ} 38037-2017$, n. ${ }^{\circ} 7$. 
do, de considerables recursos económicos. Evidentemente parece escandaloso que un medio de televisión nacional demuestre tal falta de prolijidad en la emisión de su noticiario central el cual es sintonizado por miles de personas cada día, y además haya mantenido la noticia que contenía un error de tamaña seriedad y por tanto tiempo en su plataforma en línea. Esto, aparejado con la solvencia de la demandada hace suponer que la indemnización de perjuicios exhibe características punitivas, más que estrictamente compensatorias sobre todo en lo que refiere a las víctimas indirectas. Sin embargo, lo que se pierde de vista es que a diferencia en derecho penal, donde la gravedad del delito incide en la pena asignada al autor, en derecho civil, al menos en principio, lo que interesa es la extensión del daño sufrido por la víctima ${ }^{16}$.

Respecto de las víctimas secundarias, parece inapropiada la trivialización de las referencias a la depresión, la cual es una alteración patológica del estado de ánimo a ser diagnosticada por el profesional de la salud competente, que, a su vez, no es sinónimo de mera angustia ni un simple agregado en una larga lista de manifestaciones de malestar psíquico ${ }^{17}$. Dicho de otro modo, no se condice con los avances médicos y las distinciones hechas por los profesionales de la salud ${ }^{18}$, el que dolencias patológicas, por un lado, y angustia, por el otro, sean todas sometidas sin matiz alguno a un mismo régimen de reparación.

En el ámbito teórico, cabe reiterar que la decisión tanto de primera instancia como aquella del máximo tribunal, centran la atención en las 224 consecuencias de la conducta negligente de la demandada. Al fijar los montos de la indemnización, en ambos casos lo compensado es el daño moral, sin distinción entre ambas clases de víctimas. Respecto a esto último, cabe recalcar que conceptualmente el daño moral sufrido por ambas difiere en tanto que la víctima indirecta en el sistema chileno parece ser compensada por un daño moral "puro" sin identificación del interés jurídico conculcado por la demandada, mientras que en lo referente a la víctima directa, sí hay un esfuerzo argumentativo tendiente a identificar el marco de protección del honor y reputación, y no solo la angustia experimentada.

La doctrina chilena ha identificado esta tensión entre un razonamiento anclado en pretium doloris por contraste con uno basado en la vulneración de un interés jurídico extrapatrimonial sobre todo en el contexto de daño

${ }^{16}$ Horvitz y López (2004), p. 603.

${ }^{17}$ Según las guías del Ministerio de Salud, la depresión: "Es definida operacionalmente por el Ministerio de Salud de Chile como una alteración patológica del estado de ánimo, caracterizada por un descenso del humor que termina en tristeza, acompañado de diversos síntomas y signos que persisten por a lo menos 2 semanas". Minsal (2013), p. 12.

${ }^{18}$ Corte Suprema, 24 de enero de 2019, rol n. ${ }^{\circ} 38037-2017$, n. ${ }^{\circ}$ 5: "Así también ha sido resuelto (por ejemplo, Fallos del Mes, n. ${ }^{\circ} 301$, p. 765, en cuanto el vínculo cercano de parentesco hace suponer la depresión, dolor o angustia en que se traduce el daño moral invocado)". Como se aprecia de los fallos en los cuales se ampara la decisión de la Corte Suprema en este caso, es del todo cuestionable que un vínculo de parentesco pueda hacer suponer que la víctima secundaria necesariamente habrá de sufrir depresión, sin que medie prueba alguna ni calificación respecto de la edad de tal víctima indirecta. 
moral de las personas jurídicas ${ }^{19}$. Ello redunda en la consolidación por parte de la doctrina y los tribunales de un reconocimiento de la posibilidad de indemnizar el daño moral bajo la óptica unipolar o deóntica donde lo compensado es la infracción de un interés extrapatrimonial. En lo referente a las personas naturales, este tipo de modelo ha sido impulsado en el ámbito teórico por algunos autores, precisamente en el contexto del derecho al honor y su interacción con las normas de responsabilidad civil ${ }^{20}$, a pesar de lo cual es posible apreciar que en la práctica el foco sigue estando en los perjuicios bajo su concepción bipolar o consecuencial.

\section{Marco normativo de protección del honor y la reputación en Chile}

De forma adicional, este fallo ejemplifica cómo el sistema chileno de protección del honor y la reputación ha tomado distancia del marco de protección otorgado por el derecho penal a través de los delitos de injurias y calumnias, donde también se puede ejercer la acción civil. Entre otros motivos, ello se explica por los estrictos estándares de prueba requeridos para satisfacer los presupuestos de la acción penal privada ${ }^{21}$. Si bien el alejamiento de un modelo basado en el derecho penal es bienvenido desde la perspectiva de la protección de la libertad de expresión en una sociedad democrática ${ }^{22}$, una revisión del estado actual del desarrollo del derecho privado revela la extrema amplitud del concepto de daño moral que puede tener iguales efectos silenciadores. Esto se debe, entre otros motivos, a la carencia de mecanismos de limitación respecto de las víctimas secundarias. Asignar altas sumas de dinero, sin más explicación o prueba a una víctima secundaria de tres años de edad, que habría sido perturbada por un noticiario que de modo erróneo sindicó a su padre como autor de un delito o reparar el daño moral en sede contractual, derivado de la entrega de semillas de papa de variedad diversa a la contratada ${ }^{23}$, parecen ambas estirar indebidamente la noción de daño moral. Incluso, si se aceptase la procedencia de la compensación de las víctimas

${ }^{19}$ Desde una perspectiva doctrinaria, entre otros: Diez (1997), p. 130; Domínguez (2002), p. 723; Corral (2013), p. 150. Por parte de la jurisprudencia, la última sentencia de la Corte Suprema en respaldar implícitamente el argumento que una persona jurídica no puede haber sufrido desprestigio es del año 2004, si bien la tendencia contraria, es decir, la aceptación de tal indemnización venía consolidándose ya en las décadas anteriores. Véase Ríos y SiLvA (2013) p. 124.

${ }^{20}$ Peña (2004), p. 86.

${ }^{21}$ Cabe recordar que respecto del delito de calumnias, el art. 412 del Código Penal prescribe: "Es calumnia la imputación de un delito determinado pero falso y que pueda actualmente perseguirse de oficio". Además de ello, la calumnia requiere que el agente tenga conocimiento de la falsedad objetiva de la imputación, por lo cual existe una exigencia de dolo directo, que hace que tanto hipótesis de dolo eventual como culpa sean insuficientes. GARRIDO (1998), p. 173.

${ }^{22}$ Para una revisión crítica véase Viollier y Salinas (2019).

${ }^{23}$ De la Maza (2018), p. 280. 
secundarias en un caso como el descrito, es dudoso que a tan temprana edad uno pudiese aprehender de igual modo que un adulto la implicancias del desprestigio ocasionado a otra persona por aquella noticia errónea. Sumado a ello, la indemnización global a la cual está sujeto el perjuicio moral genera opacidad puesto que no existe una subdivisión de las categorías reparables.

\section{Víctimas por rebote: \\ limitaciones a la compensación del daño moral por rebote en derecho francés e inglés y su relevancia comparada para el caso chileno}

La presente controversia permite apreciar con claridad la tendencia expansiva de la reparación del daño moral en el derecho chileno. Afirmar, como lo hace la Corte Suprema, que dada la normalidad del sufrimiento de las víctimas indirectas en casos como este, la prueba se torna irrelevante, representa un cambio respecto de posiciones jurisprudenciales anteriores. Como analizase José Luis Diez Schwerter, y con el propósito de evitar la multiplicación de acciones demandando reparación del daño moral por rebote, ya en 1983 la Corte exigía a las víctimas secundarias la acreditación de un sufrimiento real y efectivo ${ }^{24}$. De igual modo, y en ese sentido en sintonía con las limitaciones del derecho francés, los casos de compensación de la víctima por rebote estaban restringidos a hipótesis de muerte o lesión de la víctima directa ${ }^{25}$. Con

226 posterioridad las discusiones doctrinarias discurrieron en torno a la titularidad activa de la acción y su extensión al concubino o concubina.

En la misma línea, un artículo académico de 1999 de relevancia en esta área es aquel de Fabián Elorriaga, quien también circunscribía los casos más importantes de daño por rebote a lesiones corporales o muerte de la víctima inicial, procediendo a enfocarse en la pregunta más relevante para aquella época, cual era la determinación de aquellas personas que poseían legitimación activa $^{26}$. En este sentido, los principios limitativos de mayor importancia serían la determinación de la certidumbre del daño (debiendo ser este real y efectivo $\mathrm{y}$, por lo tanto, probado), y la identificación del interés legítimo lesionado ${ }^{27}$.

Es curioso que en el caso bajo análisis la Corte Suprema identifica la información divulgada por la estación de televisión como la fuente de los padecimientos sufridos, sin elaborar distinción alguna entre víctima primaria $\mathrm{y}$ víctimas secundarias ${ }^{28}$. Es posible afirmar que la diferencia entre ambas clases de víctimas es implícita por cuanto el tribunal de primera hace uso de

${ }^{24}$ Diez (1997), p. 127.

${ }^{25}$ Op. cit., pp. 127-128.

${ }^{26}$ Elorriaga (1999), p. 369.

${ }^{27}$ Op. cit., p. 373.

${ }^{28}$ Corte Suprema, 24 de enero de 2019, rol n. ${ }^{o} 38037-2017$, n. ${ }^{\circ} 2:$ "Que, en el caso, los padecimientos constitutivos de daño moral fueron originados por la información divulgada por la demandada en la edición de su noticiero central, de que el demandante (...) había cometido un ilícito penal (...)". 
la misma, lo cual no es cuestionado por la Corte Suprema. Sin embargo, al señalar que el acto negligente inicial en sí mismo es aquello que ocasiona el daño de la cónyuge e hijos, en realidad se desdibuja la distinción entre ambas clases de víctimas. Ello no es errado en teoría, pero implica que es de gran importancia determinar cómo se justifica jurídicamente la reparación en ambos casos, puesto que más que alguna especie de "rebote", se está afirmando que el mismo acto ocasiona padecimientos morales de diferentes clases, a diferentes personas. En lo que respecta al señor Valls, en primera instancia se justifica la vulneración de su derecho a la honra, pero respecto de su familia esta no puede ser la base jurídica, pues su reputación no ha sido afectada de manera alguna. La única razón para compensarles es la afectación de su integridad psíquica considerada en sí misma, y no como consecuencia de la infracción de otro interés jurídico protegido. En tal sentido, es posible constatar que lo compensado es el daño moral "puro" sufrido por las víctimas secundarias.

Por lo tanto, considerando que el primer problema con el caso objeto de este comentario es la ausencia de matiz y límites en la legitimación activa de miembros de la familia del demandante, un segundo punto que genera problemas teóricos es la aparente ausencia de límites en cuanto a las materias en las cuales es posible demandar daño moral reflejo, aparejado en tercer término, con las presunciones aplicadas por los tribunales tendientes a prescindir de la acreditación del perjuicio atendida su normalidad. Debe recordarse que en primera instancia la falta de acreditación del mismo fue la razón por la cual se negó la reparación a las víctimas por rebote, lo cual fue finalmente revertido por el máximo tribunal. En ese sentido, no parecen suficientes las limitaciones tendientes a evitar el aumento del potencial número de víctimas secundarias en atención al vínculo que tienen con el demandado, sino, también, se requiere una delimitación clara de la clase de hechos que pueden desencadenarlos, acaso solamente muerte y lesiones graves, como en otros países. E, incluso, si se aceptase una mayor amplitud de materias, es preciso justificar con mayor detalle la forma en que sus intereses han sido afectados exigiendo su correspondiente acreditación. De este modo, se evitará la expansión de la indemnización (de aceptarse que esta no puede ser punitiva, sino tiene fines estrictamente compensatorios) y, por ende, es necesario distinguir, por ejemplo, de acuerdo con las edades de tales víctimas, aun cuando tal estimación pueda ser fijada de manera discrecional por el tribunal.

\section{a) Francia}

i. Marco normativo de la protección del honor y la reputación

Desde la perspectiva del derecho francés, el caso bajo análisis estaría circunscrito por la Ley de Prensa de $1881^{29}$. Esta ley penal define los delitos de

${ }^{29}$ En cuanto a la diseminación de "noticias falsas" en Francia, cabe recalcar que con fecha 22 de diciembre de 2018, fue aprobada la Ley n. ${ }^{\circ}$ 2018-1202 contra la manipulación de in- 
injures y diffamation, y concibe, además, un plazo de prescripción de la acción sumamente corto de tres meses. En relación con ello, uno de los aspectos más reprochados por la doctrina francesa ${ }^{30}$ es la imposibilidad de aplicar las reglas comunes contenidas en la cláusula general de responsabilidad del art. 1240 (antiguo art. 1382 del Code Civil) en lo referente a la pretensión de reparación civil $^{31}$. El debate académico es de larga data y las Cortes han tendido a dudar de tal compatibilidad, adoptando una postura primariamente restrictiva que descarta de forma completa la posibilidad de fundar la responsabilidad en tal disposición ${ }^{32}$. Casos posteriores parecen haber relajado la aproximación más ortodoxa al problema, autorizando el uso del art. 1240 del Code Civil en casos que envuelven a la prensa, pero restringido únicamente a presupuestos que exhiban la ausencia de una violación clara del derecho al honor, pudiendo aplicarse las normas comunes de tal forma que la víctima puede escoger el exclusivo ejercicio de la acción civil ${ }^{33}$.

El ejemplo del derecho francés es útil para el propósito de evaluar la posición chilena. Las injurias y calumnias son consagradas como delitos de acción penal privada según el art. 55 del Código Procesal Penal ${ }^{34}$. A diferencia del caso francés, en el sistema jurídico chileno la falta de ejercicio de la acción penal privada no implica una renuncia a la pretensión civil ${ }^{35}$.

formación. Esta tiene como objetivo frenar noticias falsas o fake newes en periodos de elecciones. Como se hizo notar con anterioridad el caso analizado por el presente comentario, no muestra los rasgos típicos de las "noticias falsas" ni afecta en forma alguna un proceso de elecciones.

${ }^{30}$ VineY (2014), p. 787.

${ }^{31}$ Ejemplos de tal restricción pueden observarse en dos fallos simultáneos de la Cour de cassation, Civ. $3^{\text {e }}, 1^{\text {er }}$ décembre 2016, pourvoi $n^{\circ} 15-26.559$; Cour de cassation, Civ. $1^{\text {re }}, 16$ novembre 2016, pourvoi $n^{\circ} 15-22.155$, No publicado en el boletín. En ambos casos, y con el típico laconismo de las sentencias francesas, la corte resuelve: “(...) los abusos de la libertad de expresión previstos y sancionados por la ley de 29 de Julio de 1881 no pueden ser reparados con fundamento en el artículo 1382, convertido en el artículo 1249 del código civil (...)” (traducción propia) “(...) les abus de la liberté d'expression prévus et réprimés par la loi du 29 juillet 1881 ne peuvent être réparés sur le fondement de l'article 1382, devenu 1240, du code civil (...)".

${ }^{32}$ Société Le Figaro et autre c. Consorts Legraverend, Cour de cassation, Civ. $1^{\text {re }}, 17$ septembre 2005, pourvoi $\mathrm{n}^{\mathrm{o}}$ 03-13.622. La Corte revoca la sentencia de primera instancia sobre la base de la incompatibilidad de sancionar los abusos a la libertad de expresión bajo tal disposición:"Vu l'article 1382 du Code civil ; Attendu que les abus de la liberté d'expression envers les personnes ne peuvent être poursuivis sur le fondement de ce texte (...)".

${ }^{33}$ Cour de cassation, Civ. $1^{\text {re }}, 30$ octobre 2008 , pourvoi n ${ }^{\circ} 07-19.223$. “(...) quand l'imputation de la paternité d'une publication en l'absence de propos injurieux ou portant atteinte à l'honneur ou à la considération ne relève pas des dispositions de la loi du 29 juillet 1881, la cour d'appel a violé par fausse application les articles 29 et 53 de la loi du 29 juillet 1881 et par refus d'application l'article 1382 du code civil".

${ }^{34}$ Según el tablero penal del Poder Judicial, en 2017 ingresaron 466 causas de injurias y calumnias por medios de comunicación social (en un universo de 571261 causas ingresadas en los juzgados de garantía), de las cuales cuarenta y dos terminaron en sentencia absolutoria y doce en sentencia condenatoria. Véase tablero penal del Poder Judicial, disponible en https://public.tableau.com/profile/poder.judicial\#!/vizhome/shared/M5R57WYYY [fecha de consulta:26 de julio de 2019].

${ }^{35}$ Horvitz y López (2003), p. 339. 
El hecho que las injurias y calumnias estén sancionadas en el Código Penal, sumado a un alejamiento de la función compensatoria del derecho civil extracontractual, permiten apreciar que la protección de la reputación a través de la compensación del daño moral está enmarcada en una tendencia más general de privatización del derecho penal ${ }^{36}$. Por otro lado, en Chile no existe prohibición de usar las normas comunes de derecho civil con independencia de la acción penal, ni están supeditadas al plazo de prescripción de la acción penal como es el caso francés. En ese sentido, el régimen chileno de compensación del daño moral ocasionado por medios de prensa es manifiestamente más liberal que el derecho francés.

ii. Víctimas secundarias: préjudice moral réfléchi

\section{o préjudice d'affection par ricochet}

Respecto del daño moral sufrido por las víctimas secundarias, el panorama de protección en Francia también resulta más restrictivo que el sistema chileno de responsabilidad civil. La compensación de las víctimas de perjuicios morales reflejos, también conocido como "perjuicio de afección por rebote" experimentado por los familiares de la víctima, fue aceptada por primera ver por la Cour de cassation en $1931^{37}$. Sin embargo, este caso refiere a los perjuicios económicos provenientes del estado depresivo en que cayó la demandante luego de la muerte de su hija en un incendio ${ }^{38}$. Progresivamente, casos posteriores dan cuenta de un desarrollo de esta área, sin embargo, focalizado en casos de muerte de la víctima directa o lesiones corporales graves ${ }^{39}$. En definitiva, la compensación del daño moral de las víctimas secundarias es de larga data, en casos de muerte de la víctima principal ${ }^{40}$.

Un caso relevante dado que trata sobre la compensación por rebote en casos de difamación fue decidido en 1999 por la Cour de cassation ${ }^{41}$. La diferencia principal con la aproximación chilena es que refiere a que aquello que se extiende a otra persona por rebote es la imputación defamatoria en cuanto hecho dañoso, y no que el daño moral sea por rebote producto de los sufrimientos experimentados por un familiar de la víctima directa ${ }^{42}$, por

${ }^{36}$ HorvitZ y LóPez (2004), p. 538.

${ }^{37}$ Cass. Req., 2 février 1931, rapp. Pilon, DH, 1931, 1, p. 113-114.

${ }^{38}$ CASsOn (2009), chapitre 1, section 1, paragraphe 15.

${ }^{39}$ Por ejemplo, en Societé nationale de Chemins de fers français c. Geneix et époux Chamard, Cour de cassation, 22 octobre 1946, Recueil Dalloz, Paris, 1947, p. 59. De igual manera Balian c. Deturmeny, Cour de cassation, 29 novembre 1989, JCP, 1990, p. 31 et ss. donde se admite la compensación de la víctima secundaria en un caso de discapacidad permanente de la esposa del demandante, como consecuencia del daño establecido judicialmente cometido por negligencia médica.

${ }^{40}$ Kadner (2018), p. 358.

${ }^{41}$ Cour de cassation, Civ. $2^{\mathrm{e}}$, 11 février 1999, pourvoi no 97-10.465, Bulletin Civ. II, no 25, Paris, 1999 - Adde Crim. 23 novembre 2010, pourvoi n 09-87.527.

42 "la diffamation visant une personne ne peut rejaillir sur une autre que dans la mesure où les imputations diffamatoires lui sont étendues, fût-ce de manière déguisée ou dubitative, ou par 
lo que es del todo improbable que un caso similar al aquí comentado sea decidido de igual forma en Francia.

b) Inglaterra y Gales

i. Marco normativo de la protección del honor y la reputación

Con toda claridad este caso puede enmarcarse en el tort of defamation, y más específicamente como un slander actionable per se, dado que se trata de la imputación de comisión de un delito. Aun así, dado que en este caso se trata de un error no intencional en la identidad de la persona, habiéndosele atribuido el delito cometido por otra respecto de la cual esta sí era verídica, la Defamation Act 1996 describe un procedimiento donde la demandada admite su error, ofrece tales disculpas por escrito y las publica de forma adecuada, y llega a un acuerdo reparatorio con la víctima ${ }^{43}$.

Respecto a lo que se entiende por difamatorio, ello en general entraña que una persona razonable (right-thinking person) tendría a la víctima en menor estima ${ }^{44}$. Como es posible apreciar, el foco no está en la normalidad de sufrir o no daño moral bajo la forma de sufrimiento y angustia, sino en determinar si la publicación es o no difamatoria. El caso de Berkoff v Burchill reconoce la ausencia de definición exacta de aquello que puede considerarse "difamatorio", elaborando una enumeración de diversos usos previos hechos por los tribunales superiores ${ }^{45}$, que pueden resumirse en tres perspectivas: que la publicación tenga el efecto de disminuir la estima en que se tenía a la víctima, que esta sea evitada y rehuida, o ridiculizada ${ }^{46}$.

Hoy el art. 1 (1) de la Defamation Act 2013, en vigor en Inglaterra y Gales desde el 1 de enero de 2014 provee: "A statement is not defamatory unless its publication has caused or is likely to cause serious harm to the reputation of the claimant" ${ }^{\prime 7}$.

Dado que su entrada en vigor es relativamente reciente, los casos que lidian con la interpretación de esta norma son pocos. Entre ellos, el más importante es Lachaux v. Independent Print Ltd ${ }^{48}$ donde la Corte Suprema del Reino Unido abordó la interpretación de aquello que constituiría serious harm fijando el estándar del daño accionable. Uno de los asuntos controvertidos en dicho caso refería a que mediante la introducción de la Defamation Act 2013

voie d'insinuation", Cour de cassation, Civ. $2^{\mathrm{e}}$, 11 février 1999, pourvoi n ${ }^{\mathrm{o}}$ 97-10.465, Bulletin Civ. II, $\mathrm{n}^{\circ}$ 25, Paris, 1999 - Adde Crim. 23 novembre 2010, pourvoi $\mathrm{n}^{\circ}$ 09-87.527.

${ }^{43}$ Giliker (2017), p. 548.

${ }^{44}$ Sims v. Stretch [1936] 2 All ER 1237.

${ }^{45}$ [1997] E.M.L.R. 139, [144-6].

${ }^{46}$ Cottrell (1998), p. 150.

47 "Una afirmación no es difamatoria a menos que su publicación haya causado o sea probable que cause un daño serio a la reputación del demandante" (traducción propia).

${ }^{48}$ [2019] UKSC 27; [2019] 3 WLR 18. 
se aboliría la presunción de daño del Common Law ${ }^{49}$. En primera instancia se arguyó que el art. 1 (1) introducía un requisito adicional de probar la seriedad del daño en los hechos particulares del caso, de forma adicional a que la afirmación tuviese la aptitud de ser inherentemente injuriosa. La Corte Suprema del Reino Unido respaldó la interpretación del juez Mark Warby en primera instancia, de modo que el umbral fue elevado de una "tendencia sustancial" de afectar la actitud de otras personas respecto al demandante (cual era la posición en Thornton ${ }^{50}$ ), a un requisito de daño serio o severo (serious harm). De este modo, la Corte arguye que en realidad, más que una revolución del derecho de difamación inglés, la pieza legislativa en realidad habría introducido un requisito adicional a la aptitud inherente de las palabras de dañar la reputación, la cual no sería suficiente prueba en sí misma, sino debe estar acompañada de la acreditación de su seriedad o severidad. En Lachaux, se aceptó que la prueba de la severidad del daño podía acreditarse mediante inferencias. En este sentido, se aceptó prueba testimonial y prueba escrita de hechos tales como la gran escala de las publicaciones en periódicos, el hecho de que la publicación había llegado al conocimiento de al menos una persona identificable en el Reino Unido que conocía a Bruno Lachaux, el que fuera probable que la publicación hubiese llegado a la atención de personas que lo conocían y, por último, la gravedad de las acusaciones ${ }^{51}$.

Como es posible apreciar de la exposición anterior, la aproximación a la compensación de la vulneración a la reputación de una persona en derecho inglés difiere fundamentalmente de la justificación de la reparación en el caso chileno. Ello se debe no solo a las evidentes diferencias estructurales entre un sistema de Common Law y el derecho chileno, que es heredero de la tradición romano-canónica del derecho civil, sino, también, hay una importante diferencia en el papel de las perjuicios no pecuniarios englobados bajo el concepto de "daño moral". En Chile este último se ha erguido, sin mayor discusión de los mecanismos de limitación de la reparación, en una forma alternativa de proveer protección a derechos de la personalidad tales como el derecho a la honra y reputación. Es de suponer que un caso como el discutido en este trabajo, se satisfaría el carácter de severidad del daño impuesto por el derecho inglés. Sin embargo, hay que recalcar que ello se debe al cumplimiento del estándar requerido por el Common Law para considerar difamatoria una publicación, y no en una fundamentación anclada en el dolor o sufrimiento experimentado por la víctima. Con todo, a diferencia de casos como Lachaux, en este caso existió un error respecto de la identidad del sujeto,

${ }^{49} \mathrm{El}$ punto es de suma importancia en cuando a la mantención de la distinción tradicional entre casos que pueden ser demandados per se sin necesidad de probar perjuicios consecuenciales (actionable per se), y aquellos casos de difamación que requieren acreditación de perjuicios consecuenciales de carácter pecuniario (actionable on proof of special damage).

${ }^{50}$ [2010] EWHC 1414 (QB).

${ }^{51}$ [2019] UKSC 27, [21]. 
lo cual probablemente en Inglaterra se tramitaría por la vía del mecanismo de disculpas y reparación contemplado en la Defamation Act 1996.

La misma Corte Suprema chilena reconoce que la conducta negligente de la parte demandada fue la emisión de información objetivamente falsa a través de la cual al señor Valls le fue atribuido un hecho delictivo del cual no tuvo participación alguna. En ese sentido, la conclusión lógica es que fueron su honra y reputación los que fueron vulnerados en forma directa. Respecto de su familia, aquello que busca ser compensado por el tribunal no es la inracción del derecho a la honra, sino como se señaló con anterioridad, el daño moral "puro".

\section{ii. Víctimas secundarias}

La diferencia más clara del Common Law inglés en comparación con el derecho chileno tiene que ver con quienes pueden ser considerados víctimas secundarias, puesto que existe una serie de limitaciones a la compensación de daño moral de estas, que son, por lo demás, mucho más estrictas que en Chile.

En primer término, la regla tradicional del Common Law aplicable tanto a la víctima primaria como secundaria, es la necesidad de probar que se ha sufrido una enfermedad psiquiátrica reconocida, siendo la angustia o aflicción insuficientes en sí mismas ${ }^{52}$. Además de los requisitos comunes, existe también una serie de mecanismos de control respecto de las víctimas secundarias, que persiguen como principio de política pública la limitación del número de potenciales casos evitando así "abrir las compuertas de la litigación" (floodgates argument $)^{53}$. Esto último podría desencadenar un aumento en las primas de los seguros, además de representar un costo excesivamente oneroso para el sistema público de salud y atochar de causas en los tribunales ${ }^{54}$.

Un caso autoritativo para entender los mecanismos de control del Common Law inglés es McLoughlin v. O'Brian ${ }^{55}$. En los hechos, una madre fue alertada por su vecino del accidente de tránsito sufrido por su esposo e hijos. Al llegar al hospital la mujer se percató que su hija menor había muerto y presenció la gravedad de las heridas de su esposo y el resto de sus hijos. Como consecuencia de ello, además del shock del momento, desarrolló una

${ }^{52}$ McLoughlin v. O’Brian [1983] 1 AC 410, [431]: "El primer obstáculo que debe superar quien demanda la compensación en cuestión es establecer que está sufriendo, no mera aflicción, dolor u algún otro sentimiento normal, sino una enfermedad psiquiátrica en términos positivos" (traducción propia) "(...) the first hurdle which a plaintiff claiming damages of the kind in question must surmount is to establish that he is suffering, not merely grief, distress or any other normal emotion, but a positive psychiatric illness".

${ }^{53}$ Burrows \& Burrows (2016) described as an adjustment disorder, in seeing the condition of his wife who was the primary victim of admitted medical negligence. His claim for compensation, as a 'secondary victim', failed because he could not satisfy the legal requirement that there must be a sudden shocking event. This commentary criticises that requirement which appears to make no medical sense, p. 280.

${ }^{54}$ Ibid.

${ }^{55}$ [1983] 1 AC 410, [1982] 2 WLR 982. 
profunda depresión y cambios de personalidad. Los demandados admitieron su responsabilidad en la muerte de la niña y las lesiones sufridas por las otras víctimas del accidente, pero no así el que su conducta negligente hubiese provocado el estado de shock de la víctima secundaria. El tribunal elaboró una diferencia entre el observador común del accidente, y la clase de personas que sí pueden ser compensadas por el shock nervioso, como los familiares directos de la víctima ${ }^{56}$. De forma adicional, tales personas deben hallarse en la proximidad del accidente o el momento inmediatamente posterior a este (immediate aftermath). Por último, un tercer factor de importancia es la forma en que la enfermedad psiquiátrica fue producida, dado que se requería que la percepción del accidente fuera por vista o audición del suceso ${ }^{57}$. En un caso posterior, que es autoridad en esta materia, Alcock v. Chief Constable of South Yorkshire ${ }^{58}$ la Cámara de los Lores aprobó de maneara unánime la decisión de lord Wilberforce en McLoughlin. Los criterios fijados para el reconocimiento de la calidad de víctima secundaria para efectos de compensación pueden ser resumidos como sigue:

1. Establecer la existencia de un vínculo estrecho de amor y afección entre la víctima secundaria y la persona herida.

2. La víctima secundaria debe haber estado presente en el lugar del accidente o en el momento inmediatamente posterior, sin que la mera comunicación de noticias dolorosas sea suficiente.

3. La dolencia psiquiátrica debe haber sido causada por la percepción directa (por sus propios sentidos) del accidente o el momento inmediatamente posterior a este.

Si bien no hay una lista taxativa de los eventos respecto de los cuales la víctima secundaria puede ser compensada, se ha entendido que estos deben ser particularmente horrendos e impresionantes ${ }^{59}$. En este sentido, no hay casos que hayan cumplido estos criterios para el reconocimiento de víctima secundaria en lo relativo a infracciones a la honra y reputación de una persona, en el contexto del tort of defamation. Incluso, en casos de percepción directa,

${ }^{56}$ [1982] 2 WLR 982; [1983] 1 AC 410, [422]: "En lo que refiere a la clase de personas [con legitimación activa], el rango posibilidades está entre aquellos con los vínculos familiares más cercanos -padres e hijos, o marido y mujer- y un observador común. El derecho actual reconoce la pretensión de los primeros, pero rechaza la de los segundos, ya sea sobre la base de que se presume que tales personas deben tener la fortaleza suficiente para sobrellevar las calamidades de la vida moderna, o porque no puede esperarse que los demandados compensen al mundo en general. (Traducción propia) "As regards the class of persons, the possible range is between the closest of family ties -of parent and child, or husband and wife- and the ordinary bystander. Existing law recognises the claims of the first: it denies that of the second, either on the basis that such persons must be assumed to be possessed of fortitude sufficient to enable them to endure the calamities of modern life, or that defendants cannot be expected to compensate the world at large".

${ }^{57}$ Walton \& Armitage (2018), paragraphs 2-150.

58 [1992] 1 AC 310.

${ }^{59}$ Liverpool Women's Hospital NHS Foundation Trust v. Ronayne [2015] EWCA Civ 588; [2015] 6 WLUK 554. 
las cortes han negado la posibilidad de compensar como víctima por rebote a un hombre que alegó haber sufrido estrés postraumático (lo cual es una enfermedad psiquiátrica reconocida y no solo angustia) como consecuencia de presenciar la histerectomía realizada negligentemente a su cónyuge, y que le produjo septicemia y peritonitis. Ello se debió a que el evento no fue considerando excepcional para una persona que ha sido hospitalizada y, por tanto, no resultaba lo suficientemente "horroroso", y puesto que los eventos transcurrieron en un lapso de días, no se estaba tampoco en presencia de un evento de shock abrupto ${ }^{60}$.

De la exposición anterior es posible apreciar que en un caso como el fallado por la Corte Suprema chilena, los tribunales ingleses no compensarían los perjuicios no pecuniarios de las víctimas indirectas, pues no se cumplirían los requisitos definidos en Alcock, ni es de suponer que el evento de presenciar la noticia difamatoria por televisión pudiera considerarse suficientemente próximo ni tampoco horrendo o impresionante comparado con otros casos.

\section{CONClusiones}

Es posible apreciar una diversidad de dificultades teóricas en el razonamiento expuesto por la Corte Suprema chilena.

234 En primer lugar, el daño moral de las víctimas por rebote es "puro" en el sentido de que no está acompañado de otra infracción a los intereses jurídicos protegidos de estas. El noticiario, sin duda, afectó el honor y reputación del señor Valls, pero al indicar, por error, que este era el autor del delito, no infringió el derecho a la honra u otro derecho de la personalidad de su familia directa. En este sentido, el sistema chileno, comparado con el de otros países, como Francia e Inglaterra y Gales, aparece extremadamente liberal.

La segunda conclusión que es posible extraer de este fallo es que el daño moral se alinea con un modelo bipolar de concebir los perjuicios, donde lo que importa son las manifestaciones consecuenciales tales como: la ansiedad, depresión, angustia, entre otras. Sin embargo, se dispensa la prueba de tales perjuicios en tanto sufrirlos sería "lo normal".

En tercer término, este caso permite ilustrar cómo el límite entre víctimas directas e indirectas de desdibuja, si se considera que la Corte basa la responsabilidad de la demandada respecto de las víctimas por rebote en el mismo hecho dañoso inicial, cual es la emisión noticiosa.

En cuarto lugar, es posible apreciar un grado de arbitrariedad difícil de justificar en la fijación de los montos de indemnización. Incluso, si se llegase a la conclusión que los miembros de la familia directa del demandante pudiesen ser considerados víctimas secundarias, no fueron justificadas apropiadamente

${ }^{60}$ Liverpool Women's Hospital NHS Foundation Trust v Ronayne [2015] EWCA Civ 588; [2015] 6 WLUK 554, [41]. 
las diferencias hechas entre estos, las cuales llevan a que la cónyuge reciba un monto de dinero mayor que un hijo mayor de edad. Tampoco queda claro el motivo por el cual ese mismo hijo mayor de edad fue compensado por el mismo monto que su hermana de tres años al momento de los hechos. Difícilmente podría pensarse que un infante que no atiende al colegio pueda sufrir socialmente los mismos malos ratos que un adolescente o adulto con completa comprensión de los efectos de la publicación difamatoria.

Una quinta observación que se desprende del análisis de este caso es la ausencia de distinción y matices en el trato que da el derecho a fenómenos de ansiedad, molestias, dolor, humillación y enfermedades psiquiátricas propiamente tales. Todos estos conceptos son empleados de manera indistinta y sin calificación que atienda a sus usos médicos y características patológicas de algunos.

En sexto lugar, cabe hacer presente que el marco jurídico de protección del honor y la reputación de una persona se ve subsumido en el concepto amplio de daño moral, que como categoría abierta permite la reparación sin mayor indagatoria del interés jurídico protegido. En ese sentido, a diferencia de otros ordenamientos el sistema chileno no distingue entre un caso en que el demandante presencia la muerte en circunstancias horrendas de un ser querido, del casos de infracciones a la honra. A ello se suma la ausencia de ciertos mecanismos de limitación del daño moral por rebote como una clase particularmente grave de eventos que pueden gatillar la compensación o la delimitación de la naturaleza de la lesión psiquiátrica requerida, contrario a lo que ocurre tanto en el caso francés como inglés y galés.

Por último, la pregunta lógica que deriva de todas las consideraciones anteriores es si no son acaso las funciones del derecho de responsabilidad civil aquello que está mutando. Parece ser que este caso tiene que ver más con la imposición de una pena privada a la parte demandada, el canal de televisión, quien por lo demás tiene los "bolsillos más profundos", que verdaderamente estar anclado en la reparación de los perjuicios experimentados por la víctima. Ello representa un alejamiento del principio de reparación integral bajo su concepción compensatoria, todo lo cual, si bien podría ser defendido en teoría, requiere elaboración doctrinal más acabada y soporte legal claro. Sin ello, en contraste con otras jurisdicciones como el Common Law Inglés que consagra de forma explícita otros objetivos más allá de la compensación, bajo las formas de vindication y daños punitivos (exemplary damages), el modelo chileno sigue adherido, en teoría, exclusivamente a la compensación del daño, pero incluyendo otra clase de razonamientos que transitan hacia la punición.

Más allá de los evidentes problemas en lo que respecta la avaluación del daño moral, queda claro que la jurisprudencia chilena parece ir a contracorriente de las tendencias en derecho comparado, liberalizando aún más la compensación de los perjuicios no pecuniarios, en vez de ahondar en sus mecanismos de limitación. 


\section{BIBLIOGRAFÍA CITADA}

Burrows, Andrew \& John Burrows (2016). "A shocking requirement in the law on negligence liability for psychiatric illness: Liverpool Women's Hospital NHS Foundation Trust v Ronayne [2015] EWCA CIV 588". Medical Law Review, vol. 24, $\mathrm{n}^{\mathrm{O}}$ 2. Oxford.

Casson, Phillipe (2009). Répertoire de droit civil. Paris: Dalloz.

Corral TAlciani, Hernán (2013). Lecciones de responsabilidad civil extracontractual. Santiago: Editorial Jurídica de Chile.

Cottrell, Jill (1998). "What Does 'Defamatory' Mean? Reflections on Berkoff v. Burchill”. Tort Law Review, $\mathrm{n}^{\circ}$ 6. North Ryde, NSW, Australia.

DE la MAZA, Iñigo (2018). "El daño moral en materia contractual: la mirada de la Corte Suprema”. Revista Chilena de Derecho, vol. 45, n. ' 2. Santiago.

Descheemaeker, Eric (2016). "Unravelling harms in Tort Law". Law Quarterly Reviere, vol. 132. London.

Diez Schwerter, José Luis (1997). El daño extracontractual: jurisprudencia y doctrina. Santiago: Editorial Jurídica de Chile.

Domínguez Hidalgo, Carmen (2002). El daño moral. Santiago: Editorial Jurídica de Chile.

Elorriaga, Fabián (1999). "Del daño por repercusión o rebote". Revista Chilena de Derecho, vol. 26, n. ${ }^{\circ}$ 2. Santiago.

Garrido Montt, Mario (1998). Derecho penal: Parte general. Santiago: Editorial Jurídica de Chile. Tomo 3.

GiLiker, Paula (2017). Tort. $6^{\text {th }}$ ed. London: Sweet \& Maxwell.

Horvitz, María Inés y Julián López (2003). Derecho procesal penal chileno. Santiago: Editorial Jurídica de Chile. Tomo I.

Horvitz, María Inés y Julián López (2004). Derecho procesal penal chileno. Santiago: Editorial Jurídica de Chile. Tomo II.

Kadner Graziano, Thomas (2018). Comparative tort law: cases, materials and exercises. London-New York: Routledge, Taylor \& Francis Group.

Lambert-Faivre, Yvonne, Stéphanie Porchy-Simon (2015). Droit du dommage corporel: systèmes d'indemnisation. $8^{\mathrm{a}}$ ed. Paris: Dalloz.

Minsal (2013). Guía clínica depresión en personas de 15 años o más. Santiago.

PEÑA, Carlos (2004). "Informe sobre el proyecto de ley de protección del honor y la intimidad de las personas”. Cuadernos de Análisis Jurídicos, vol. 1. Santiago.

Ríos, Ignacio y Rodrigo Silva (2013). "Daño moral a las personas jurídicas: ¿Qué ha dicho nuestra jurisprudencia?”. Revista de Estudios de la Justicia, vol. 18. Santiago.

TAndoc, Edson, Zheng Wei Lim \& Richard Ling (2018). "Defining 'Fake News'”. Digital Journalism, vol. 6, $\mathrm{n}^{\mathrm{O}}$ 2. Abingdon. 
VINEY, Geneviève (2014). "La sanction des abus de la liberté d'expression”. Recueil Dalloz, vol. 787. Paris.

Viollier, Pablo, Matías Salinas (2019). "La tipificación de los delitos de injuria y calumnia y su efecto inhibitorio en el ejercicio de la libertad de expresión en Chile”. Anuario de Derechos Humanos, vol. 15, n. ${ }^{\circ}$ 1. Santiago. 31 de julio de 2019.

Walton, Christopher \& Mark Armitage (2018). Charlesworth \& Percy on negligence. 14th ed. London: Sweet \& Maxwell, Thomson Reuters.

SigLA Y ABREVIATURAS

AC Appeal Cases

ADR annual percentage rate

al. alii (otros)

All ER All England Law Reports

ANID Agencia Nacional de Investigación y Desarrollo

art. artículo

arts. artículos

CAE carga anual equivalente

CC Código Civil

CE Comunidad Europea

CEE $a$ veces EEC Comunidad Económica Europea

Civ. Chambre civile de la Cour de cassation

Conar Consejo de Autorregulación y Ética Publicitaria

cons. considerando

coord. coordinador

coords. coordinadores

CS Corte Suprema

DCFR Marco Común de Referencia

D.H. Dalloz (Hebdomadaire)

dirs. directores

DS decreto supremo

ed. edición a veces editor, editorial

eds. editores

E.M.L.R. Entertainment and Media Law Reports

EWCA Court of Appeal of England and Wales

EWHC High Court of Justice of England and Wales 


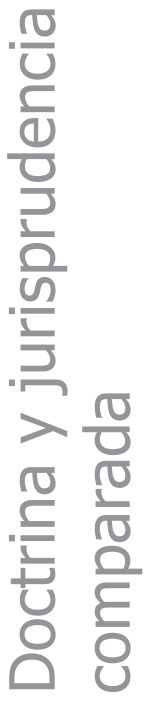

238 etc. etcétera

http Hypertext Transfer Protocol

Ltd. limited

Ibid. Ibidem

JCP La semanine juridique

n. ${ }^{\circ}$ a veces $\mathrm{N}^{\circ}$ número

op. cit. opere citato (obra citada)

p. página

PIB Producto Interno Bruto

pp. páginas

QB Queen's Bench division

rapp rapporteur

Req. Chambre des requêtes

S.A. sociedad anónima

sec. sección

Sr. Señor

UE Unión Europea

UKSC Supreme Court of the United King-

v. dom

vol. versus volumen

WLR Weekly Law Repots

WLUK Westlaw UK

www. World Wide Web 